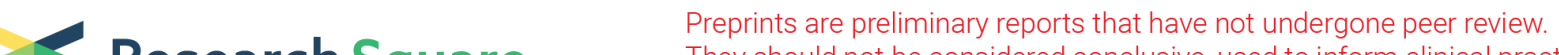 $\begin{array}{ll}\text { Research Square } & \text { They should not be considered conclusive, used to inform clinical practice, } \\ \text { or referenced by the media as validated information. }\end{array}$
}

\section{Sequential Therapy of LMWH and Rivaroxaban in the Initial Treatment of Patients With Acute Pulmonary Embolism}

\section{Wei Xiong ( $\nabla$ xiongwei@xinhuamed.com.cn )}

Shanghai Jiaotong University School of Medicine Xinhua Hospital https://orcid.org/0000-0003-21268535

\section{Yunfeng Zhao}

Shanghai Punan Hospital

$\mathrm{He} \mathrm{Du}$

Tongji University Affiliated Shanghai Pulmonary Hospital

\section{Yanmin Wang}

Shanghai Jiaotong University School of Medicine Xinhua Hospital

\section{Xuejun Guo}

Shanghai Jiaotong University School of Medicine Xinhua Hospital

\section{Wenjie Li}

Shanghai Jiaotong University School of Medicine Xinhua Hospital

\section{Song Liu}

Shanghai Jiaotong University School of Medicine Xinhua Hospital

\section{Research}

Keywords: Acute Pulmonary Embolism, LMWH, Rivaroxaban, Initial Treatment, Sequential Therapy

Posted Date: June 29th, 2021

DOI: https://doi.org/10.21203/rs.3.rs-636972/v1

License: (c) (i) This work is licensed under a Creative Commons Attribution 4.0 International License. Read Full License 


\section{Abstract}

Background: Sequential low molecular weight heparin(LMWH) plus warfarin, LMWH plus edoxaban as well as LMWH plus dabigatran regimens have already showed efficacy and safety in the treatment of acute pulmonary embolism(PE). The efficacy and safety of sequential LMWH plus rivaroxaban regimen in the treatment of PE has been understudied.

Methods: A retrospective study was performed to explore the efficacy and safety of sequential therapy regimens of subcutaneous $\mathrm{LMWH}$ (nadroparin $4100 \mathrm{IU}$ every 12 hours for a week) followed by oral rivaroxaban(20mg once daily for 3 months) in the management of patients with established acute PE without hemodynamic instability, compared with those of LMWH plus dabigatran as well as LMWH plus warfarin.

Results: The number of patients with total resolution of PE were 238(80.1\%), 220(78.0\%) and 166(62.6\%), in the LMWH+rivaroxaban, $\mathrm{LMWH}+$ dabigatran, and $\mathrm{LMWH}+$ warfarin groups, respectively. $(P=0.001)$ The prevalence of DVT at the 3-month follow-up visit were 18(6.1\%), 14(5.0\%) and 11(4.2\%), in the aforementioned three groups, respectively. $(P=0.559)$ The NT-proBNP level $(\mathrm{pg} / \mathrm{mL})$ at the 3-month followup visit were 122.5(97.4-158.9) , 131.7(102.2-166.3), and 357.8(275.4-433.2) in three groups, respectively. $(P=0.001)$ The $D$-dimer level $(\mathrm{ng} / \mathrm{mL})$ at the 3-month follow-up visit were 387.3(310.9-465.2) , 432.5(382.4489.6), and 854.0(721.5-993.7) in three groups, respectively. $(P<0.001)$ The number of patients with major bleeding events were $3(0.9 \%), 6(1.8 \%)$, and $18(5.5 \%)$ in three groups, respectively. $(P<0.001)$

Conclusions: The regimen of sequential subcutaneous LMWH for a week followed by oral rivaroxaban at a dose of $20 \mathrm{mg}$ once daily for three months is effective and safe in the initial treatment of patients with acute pulmonary embolism.

\section{Introduction}

Venous thromboembolism (VTE) is broadly defined as pulmonary embolism (PE), deep venous thrombosis (DVT), superficial vein thrombosis (SVT), and/or splanchnic vein thrombosis (SPVT), ${ }^{1}$ whereas narrowly defined as PE and/or DVT. 2,3 Epidemiological statistics demonstrated that annual incidence rates range from 39-115 per 100000 population for $P E$, whereas incidence rates range from 53-162 per 100000 population for DVT. Acute PE is the third most frequent acute cardiovascular syndrome behind myocardial infarction and stroke globally. ${ }^{2,3}$

Systemic thrombolysis is usually used in PE patients with hemodynamic instability, whereas anticoagulation is applicable to those without hemodynamic instability. ${ }^{2,3}$ Anticoagulation options recommended for the management of PE include monotherapy regimens that use only one type of agent as well as combination therapy regimens that use more than one type of agent. ${ }^{1}$ Monotherapy regimens primarily include low molecular weight heparin $(\mathrm{LMWH})$, fondaparinux, rivaroxaban, and apixaban. Combination therapy regimens primarily comprise sequential LMWH plus vitamin $\mathrm{K}$ antagonist(VKA), and LMWH plus direct oral anticoagulants (DOACs) that mainly include edoxaban and dabigatran. ${ }^{1-6}$ 
Sequential LMWH plus warfarin, LMWH plus edoxaban as well as LMWH plus dabigatran regimens have already showed efficacy and safety in previous clinical trials. ${ }^{1-6}$ Instead of rivaroxaban montherapy which is rivaroxaban $15 \mathrm{mg}$ twice daily for 21 days followed by $20 \mathrm{mg}$ once daily, sequential subcutaneous LMWH for 5 to 10 days followed by oral rivaroxaban $20 \mathrm{mg}$ once daily is a prevalent regimen for the management of patients with acute PE in China. Nevertheless, the efficacy and safety of such regimen has not been sufficiently assessed to date. Accordingly, this study was designed to investigate the the efficacy and safety of combination therapy regimens of sequential LMWH followed by rivaroxaban in the management of patients with acute PE.

\section{Methods}

\section{Study Design}

A retrospective study was performed to explore the efficacy and safety of sequential therapy regimens of subcutaneous LMWH followed by oral rivaroxaban at a dose of $20 \mathrm{mg}$ once daily in the management of patients with established acute PE which included symptomatic or incidental PE without hemodynamic instability. The efficacy and safety were compared among LMWH + rivaroxaban group in which patients received sequential LMWH plus rivaroxaban, $\mathrm{LMWH}+$ dabigatran group in which patients received sequential LMWH plus dabigatran, and LMWH + warfarin group in which patients received sequential LMWH plus warfarin, from the baseline which was defined as the diagnoses of acute PE through the 3month follow-up. Based on the matching of body weight, anatomical extent of $\mathrm{PE}^{7}$, and DVT prevalence, the proportion of number of patients in the aforementioned three groups were determined to be approximately 1:1:1.

LMWH were subcutaneous nadroparin at a dose of $4100 \mathrm{IU}$ every 12 hours for a week. Rivaroxaban was at a dose of $20 \mathrm{mg}$ once daily for three months following LMWH. Dabigatran was at a dose of $150 \mathrm{mg}$ twice daily for three months following LMWH. Warfarin was at a dose of $2.5-5 \mathrm{mg}$ once daily concurrently with LMWH for at least 5 days until an international normalized ratio (INR) $\geq 2.0$ for 24 hours. Then the dose of warfarin was adjusted to maintain an INR of 2.0-3.0 for three months.

The primary outcomes were the results of reexamination of PE at the follow-up visit after 3 months of aforementioned anticoagulant treatment. Reexamination of PE was performed by using computed tomography pulmonary angiography (CTPA) and/or planar ventilation/perfusion (V/Q) scan. Based on the results of reexamination of $P E$, patients were dichotomized into the resolution group that was defined as the absence of PE on CTPA and V/Q scan, and the non-resolution group that was defined as the remnant presence of PE on CTPA and/or V/Q scan. The resolution rate of PE in each group was compared among the $\mathrm{LMWH}$ + rivaroxaban, $\mathrm{LMWH}+$ dabigatran, and $\mathrm{LMWH}+$ warfarin groups. The resolution rate of $\mathrm{PE}$ in each group was defined as the proportion of number of patients whose PE were resolved in the total number of patients of each group at the 3-month follow-up visit. Another primary outcome was the prevalence of DVT on compression ultrasonography(CUS) in each group at the 3-month follow-up visit. The prevalence of DVT were compared among the aforementioned three groups. 
The secondary outcomes were the cardiac troponin I level, NT-proBNP level, D-dimer, and probability of pulmonary hypertension $(\mathrm{PH})$ on transthoracic echocardiogram at the 3-month follow-up visit. Probability of $\mathrm{PH}$ was dichotomized into $\mathrm{PH}$-likely and $\mathrm{PH}$-unlikely based on the criteria in guidelines. ${ }^{2,3}$ The cardiac troponin I level, NT-proBNP level, D-dimer and the prevalence of PH-likely patients at the 3-month follow-up visit were compared among the $\mathrm{LMWH}+$ rivaroxaban, $\mathrm{LMWH}+$ dabigatran, and $\mathrm{LMWH}+$ warfarin groups. The level change of troponin I, NT-proBNP, and D-dimer from the baseline through the 3-month follow-up visit were also compared among the aforementioned three groups.

The third outcomes were the events of progressed fatal PE for which thrombectomy, vena cava filter insertion, or thrombolysis were performed or indicated, the death from fatal PE, and the compelled discontinuation of anticoagulation including reduction or cessation due to adverse events, during the 3month treatment of acute PE. Fatal PE was defined as PE with hemodynamic instability due to PE. Adverse events were defined as bleeding including major bleeding and minor one. Major bleeding was defined as fatal bleeding, and/or symptomatic bleeding in a critical area or organ, and/or a fall in hemoglobin level of $20 \mathrm{~g} / \mathrm{L}$ or more, or a transfusion of two or more units of whole blood or red cells due to bleeding. ${ }^{8}$ Bleeding that did not conform to major bleeding was defined as minor bleeding. The third outcome were compared among the $\mathrm{LMWH}$ + rivaroxaban, $\mathrm{LMWH}+$ dabigatran, and LMWH + warfarin groups.

The principal safety outcomes were major bleeding from the initiation of anticoagulation through the 3month follow-up visit. Major bleeding rates were compared among the LMWH + rivaroxaban, $\mathrm{LMWH}+$ dabigatran, and LMWH + warfarin groups. Major bleeding rate was defined as the percentage of patients with at least one episode of major bleeding in each group. For patients with major bleeding, anticoagulation was ceased and not recovered until the bleeding stopped. A vena cava filter insertion or thrombectomy was performed in case of persistent bleeding.

The primary and secondary outcomes were not compared among the aforementioned three groups for patients with progressed fatal PE for which thrombectomy, vena cava filter insertion, or thrombolysis were performed, those who died of fatal PE resulted from the progression of $\mathrm{PE}$, and those whose anticoagulant was reduced or ceased due to adverse events, during the 3-month treatment of acute PE.

The current study was performed by the investigators of Shanghai Xinhua Hospital, Shanghai Pulmonary Hospital, and Shanghai Punan Hospital. All data needed for the study were retrieved from the electronic medical records system(EMRS) of each participating hospital. All authors vouch for the completeness and accuracy of the data. No one who is not an author contributed to the writing of the manuscript. The study protocol was approved by the institutional review board of each participating hospital.

\section{Study Population}

Eligible patients from each participating hospital were retrospectively incorporated into the current study based on the inclusion and exclusion criteria. The inclusion criteria comprised:1) all eligible patients were 18 years old or older; 2)all eligible patients were diagnosed with an established acute PE without hemodynamic instability by using CTPA and/or V/Q scan; 3)all patients underwent anticoagulation from the baseline through the following 3 months. The exclusion criteria comprised:1)patients who were 
ineligible to receive anticoagulation due to contraindications ${ }^{1,5} ; 2$ )patients who had a history of chronic thromboembolic disease(CTED) $)^{2,3}$; 3 ) patients who received anticoagulation prior to the diagnoses of acute $\mathrm{PE}$ and/or other anticoagulants besides the aforementioned regimens during the 3-month treatment of acute PE.

\section{Statistical Analyses}

Measurement data were presented as mean \pm standard deviation or median with interquartile range based on if they conformed to normal distribution. Categorical data were presented as percentages. The comparison of measurement data among $\mathrm{LMWH}$ + rivaroxaban, $\mathrm{LMWH}+$ dabigatran, and $\mathrm{LMWH}+$ warfarin groups was performed by using analysis of variance(ANOVA). The comparison of rates was performed by Chi-square test. The comparison of time-to-event cumulative fatal PE events, death due to fatal $\mathrm{PE}$, compelled anticoagulant reduction or cessation due to adverse events, and major bleeding events among the aforementioned three groups was performed by using Kaplan-Meier method. Statistical analyses was performed by using SPSS 26 . Statistical significance was defined as a P value being less than 0.05 .

\section{Results}

\section{Demographics and Characteristics of Patients}

Based on inclusion criteria, the data of a total of 1223 eligible patients from Jan, 2010 through Dec, 2020 were retrieved from the EMRS of Shanghai Xinhua Hospital, Shanghai Pulmonary Hospital, and Shanghai Punan Hospital. In the light of exclusion criteria, 55 patients who had a history of CTED and 158 patients who received other anticoagulants besides the aforementioned regimens during the 3-month treatment of acute PE were excluded. Finally, a total of 1010 patients with acute PE entered into the final analyses procedure. The number of patients in the $\mathrm{LMWH}$ + rivaroxaban group, $\mathrm{LMWH}+$ dabigatran group, and $\mathrm{LMWH}+$ warfarin group were 343,338 and 329 at the baseline, respectively. The median age of all patients was 65.6 years old. The number of male and female patients were 563 and 447, respectively. (Fig. 1) The demographic and clinical characteristic of all eligible patients at the baseline were summarized in Table 1. 
Table 1

Demographics and Characteristics of Patients at the Baseline

\begin{tabular}{|c|c|c|c|c|}
\hline Variables & $\begin{array}{l}\text { LMWH + rivaroxaban } \\
(\mathrm{n}=343)\end{array}$ & $\begin{array}{l}\text { LMWH + dabigatran(n } \\
=338)\end{array}$ & $\begin{array}{l}\text { LMWH + warfarin } \\
(n=329)\end{array}$ & $\begin{array}{l}P \\
\text { value }\end{array}$ \\
\hline Mean age-yr & $65.6(53.6-76.4)$ & $67.3(54.5-79.2)$ & $63.9(55.2-75.3)$ & 0.781 \\
\hline $\begin{array}{l}\text { Male sex- } \\
\text { no. (\%) }\end{array}$ & $181(52.8)$ & $205(60.7)$ & $177(53.8)$ & 0.077 \\
\hline $\begin{array}{l}\text { Weight-no. } \\
(\%)\end{array}$ & $62.5(52.1-77.3)$ & 65.1(53.5-78.9) & 63.8(51.8-76.4) & 0.886 \\
\hline $\begin{array}{l}\text { Creatinine } \\
\text { clearance- } \\
\text { no. }(\%)\end{array}$ & $97.4(74.2-120.3)$ & $110.5(87.29-140.4)$ & 78.3(58.3-101.5) & 0.038 \\
\hline $\begin{array}{l}\text { Platelet } \\
\text { count- } \\
\times 10^{9} / L\end{array}$ & $306.2(266.7-453.9)$ & $319.4(257.7-365.8)$ & $278.5(230.8-324.5)$ & 0.063 \\
\hline \multirow{2}{*}{$\begin{array}{l}\text { Diagnostic } \\
\text { methods-no. } \\
(\%)\end{array}$} & $275(80.2)$ & 283(83.7) & $245(74.5)$ & 0.082 \\
\hline & 68(19.8) & $55(16.3)$ & $98(25.5)$ & \\
\hline \multicolumn{5}{|l|}{$\begin{array}{l}\text { CTPA and } \\
\text { V/Q } \\
\text { scanning }\end{array}$} \\
\hline \multicolumn{5}{|l|}{$\begin{array}{l}\mathrm{V} / \mathrm{Q} \\
\text { scanning }\end{array}$} \\
\hline \multirow{2}{*}{$\begin{array}{l}\text { Risk strata } \\
\text { of PE-no. } \\
(\%)\end{array}$} & $241(70.3)$ & $226(66.9)$ & 235(71.4) & 0.923 \\
\hline & 102(29.7) & 112(33.1) & $94(28.6)$ & \\
\hline \multicolumn{5}{|l|}{$\begin{array}{l}\text { Intermediate } \\
\text { risk }\end{array}$} \\
\hline Low risk & & & & \\
\hline
\end{tabular}

Note: LMWH:Low Molecular Weight Heparin, CTPA:Computed Tomography Pulmonary Angiography, V/Q:Ventilation/perfusion (lung scintigraphy), PE:Pulmonary Embolism, DVT:Deep Venous Thrombosis, VTE:Venous Thromboembolism,TNI:Troponin I, NT-proBNP:N-terminal pro B-type Natriuretic Peptide, PH:Pulmonary Hypertension 


\begin{tabular}{|c|c|c|c|c|}
\hline Variables & $\begin{array}{l}\text { LMWH + rivaroxaban } \\
(\mathrm{n}=343)\end{array}$ & $\begin{array}{l}\text { LMWH + dabigatran(n } \\
=338)\end{array}$ & $\begin{array}{l}\text { LMWH + warfarin } \\
(n=329)\end{array}$ & $\begin{array}{l}P \\
\text { value }\end{array}$ \\
\hline \multirow{2}{*}{$\begin{array}{l}\text { Anatomical } \\
\text { extent of } \\
\text { PE-no. (\%) }\end{array}$} & $50(14.6)$ & $48(14.2)$ & $49(14.9)$ & \multirow[t]{5}{*}{0.958} \\
\hline & $208(60.6)$ & $206(60.9)$ & 197(59.9) & \\
\hline $\begin{array}{l}\text { Limited: } \\
\leq 25 \% \text { of } \\
\text { vasculature } \\
\text { of a single } \\
\text { lobe }\end{array}$ & $85(24.8)$ & $84(24.9)$ & $83(25.2)$ & \\
\hline \multicolumn{4}{|l|}{ Intermediate } & \\
\hline \multicolumn{4}{|l|}{$\begin{array}{l}\text { Extensive: } \\
\text { multiple } \\
\text { lobes and > } \\
25 \% \text { of } \\
\text { entire } \\
\text { pulmonary } \\
\text { vasculature }\end{array}$} & \\
\hline $\begin{array}{l}\text { Concurrent } \\
\text { DVT-no. (\%) }\end{array}$ & $86(25.1)$ & $110(32.5)$ & $91(27.7)$ & 0.071 \\
\hline $\begin{array}{l}\text { Cause of } \\
\text { PE-no. (\%) }\end{array}$ & $216(63.0)$ & $201(59.5)$ & $226(68.7)$ & \multirow[t]{2}{*}{0.036} \\
\hline $\begin{array}{l}\text { Unprovoked } \\
\text { Provoked }\end{array}$ & 127(37.0) & $137(40.5)$ & 103(31.3) & \\
\hline $\begin{array}{l}\text { Previous } \\
\text { history of } \\
\text { VTE-no. (\%) }\end{array}$ & $72(21.0)$ & $111(32.8)$ & $95(28.9)$ & 0.025 \\
\hline $\mathrm{TNl}-\mathrm{ng} / \mathrm{mL}$ & $0.3(0.1-0.5)$ & $0.5(0.2-0.8)$ & $0.2(0.1-0.3)$ & 0.020 \\
\hline $\begin{array}{l}\text { NT-proBNP- } \\
\mathrm{pg} / \mathrm{mL}\end{array}$ & 1298.3(1093.2-1520.3) & 1582.4(1239.8-1933.4) & $1321.8(1022.6-1643.1)$ & 0.066 \\
\hline $\begin{array}{l}\text { D-dimer- } \\
\mathrm{ng} / \mathrm{mL}\end{array}$ & 2318.4(1987.3-2709.5) & 1891.3(1443.7-2308.8) & $1465.9(1033.3-1840.9)$ & 0.034 \\
\hline $\begin{array}{l}\text { PH-likely-no. } \\
(\%)\end{array}$ & $65(19.0)$ & 78(23.1) & $70(21.3)$ & 0.631 \\
\hline $\begin{array}{l}\text { Note: LMWH:L } \\
\text { V/Q:Ventilatio } \\
\text { Thrombosis, } \\
\text { Natriuretic Pe }\end{array}$ & $\begin{array}{l}\text { Molecular Weight Hep } \\
\text { perfusion (lung scintigr } \\
\text { E:Venous Thromboemb } \\
\text { de, PH:Pulmonary Hype }\end{array}$ & $\begin{array}{l}\text { ר, CTPA:Computed Tomo } \\
\text { y), PE:Pulmonary Emboli } \\
\text { m,TNI:Troponin I, NT-proE } \\
\text { sion }\end{array}$ & $\begin{array}{l}\text { raphy Pulmonary Angiogr } \\
\text { m, DVT:Deep Venous } \\
\text { NP:N-terminal pro B-type }\end{array}$ & \\
\hline
\end{tabular}

\section{Primary Outcomes}


After the subtraction of patients with fatal PE including those died from fatal PE, and those with compelled anticoagulant reduction or cessation due to adverse events during the 3-month follow-up, 297, 282, and 265 patients in the $\mathrm{LMWH}$ + rivaroxaban, $\mathrm{LMWH}$ + dabigatran, and $\mathrm{LMWH}+$ warfarin groups finished the entire 3-month treatment of PE, respectively. (Fig. 1) Based on the results of PE imaging reexamination at the 3-month follow-up visit, the number of patients with total resolution of PE were 238(80.1\%), 220(78.0\%) and 166(62.6\%), in the LMWH + rivaroxaban, $\mathrm{LMWH}+$ dabigatran, and $\mathrm{LMWH}+$ warfarin groups, respectively. $(P=0.001)$ Based on the results of CUS at the 3-month follow-up visit, the prevalence of DVT were $18(6.1 \%), 14(5.0 \%)$ and $11(4.2 \%)$, in the the aforementioned three groups, respectively. $(P=0.559)$ (Table 2)

Table 2

Primary and Secondary Outcomes at the 3-month Follow-up Visit

\begin{tabular}{|c|c|c|c|c|}
\hline Variables & $\begin{array}{l}\text { LMWH + rivaroxaban } \\
(\mathrm{n}=297)\end{array}$ & $\begin{array}{l}\text { LMWH + dabigatran } \\
(\mathrm{n}=\mathbf{2 8 2})\end{array}$ & $\begin{array}{l}\text { LMWH + warfarin } \\
(n=265)\end{array}$ & $\begin{array}{l}P \\
\text { value }\end{array}$ \\
\hline \multirow{2}{*}{$\begin{array}{l}\text { Primary } \\
\text { outcome } \\
\text { Total } \\
\text { resolution-no. } \\
(\%)\end{array}$} & $238(80.1)$ & $220(78.0)$ & $166(62.6)$ & 0.001 \\
\hline & $18(6.1)$ & $14(5.0)$ & $11(4.2)$ & 0.559 \\
\hline \multicolumn{5}{|l|}{$\begin{array}{l}\text { DVT } \\
\text { prevalence-no. } \\
(\%)\end{array}$} \\
\hline \multirow{2}{*}{$\begin{array}{l}\text { Secondary } \\
\text { outcome }\end{array}$} & $0.2(0.1-0.3)$ & $0.3(0.1-0.5)$ & $0.1(0.0-0.2)$ & 0.095 \\
\hline & $122.5(97.4-158.9)$ & $131.7(102.2-166.3)$ & $357.8(275.4-433.2)$ & 0.001 \\
\hline \multirow{2}{*}{$\begin{array}{l}\text { TNI-ng/mL } \\
\text { NT-proBNP- } \\
\text { pg/mL }\end{array}$} & $387.3(310.9-465.2)$ & $432.5(382.4-489.6)$ & $854.0(721.5-993.7)$ & \multirow{2}{*}{$\begin{array}{l}< \\
0.001\end{array}$} \\
\hline & $0.1(0.0-0.2)$ & $0.2(0.1-0.3)$ & $0.1(0.0-0.2)$ & \\
\hline \multirow{2}{*}{$\begin{array}{l}\text { D-dimer- } \\
\mathrm{ng} / \mathrm{mL}\end{array}$} & 1175.8(885.6-1473.7) & 1450.7(1009.5-1857.4) & $963.6(765.7-1255.7)$ & \multirow{2}{*}{0.001} \\
\hline & $1932.4(1256.8-2674.2)$ & 1460.4(1047.3-1884.7) & 611.4(478.5-833.7) & \\
\hline $\begin{array}{l}\text { Change of TNI- } \\
\mathrm{ng} / \mathrm{mL}\end{array}$ & $6(2.0)$ & $8(2.8)$ & $7(2.6)$ & $\begin{array}{l}<.001 \\
0.001\end{array}$ \\
\hline $\begin{array}{l}\text { Change of NT- } \\
\text { proBNP-pg } / \mathrm{mL}\end{array}$ & & & & 0.285 \\
\hline \multicolumn{5}{|l|}{$\begin{array}{l}\text { Change of D- } \\
\text { dimer-ng } / \mathrm{mL}\end{array}$} \\
\hline \multicolumn{5}{|l|}{$\begin{array}{l}\text { PH-likely-no. } \\
\text { (\%) }\end{array}$} \\
\hline
\end{tabular}


The cardiac troponin I level $(\mathrm{ng} / \mathrm{mL})$ at the 3-month follow-up visit were $0.2(95 \%$ confidence interval[ $[\mathrm{Cl}]$ 0.1-0.3), 0.3(0.1-0.5), and 0.1 (0.0-0.2) in the LMWH + rivaroxaban $(n=297), L M W H+$ dabigatran $(n=282)$, and LMWH + warfarin $(\mathrm{n}=265)$ groups, respectively. $(\mathrm{P}=0.095)$ The NT-proBNP level $(\mathrm{pg} / \mathrm{mL})$ at the 3month follow-up visit were 122.5(97.4-158.9), 131.7(102.2-166.3), and 357.8(275.4-433.2) in aforementioned three groups, respectively. $(P=0.001)$ The $D$-dimer level $(\mathrm{ng} / \mathrm{mL})$ at the 3-month follow-up visit were 387.3(310.9-465.2), 432.5(382.4-489.6), and 854.0(721.5-993.7) in the aforementioned three groups, respectively. $(\mathrm{P}<0.001)$ The number of $\mathrm{PH}$-likely patients at the 3-month follow-up visit were $6(2.0 \%), 8(2.8 \%)$ and $7(2.6 \%)$ in the aforementioned three groups, respectively. $(P=0.285)$ The median level of troponin I, NT-proBNP and D-dimer all declined at the 3-month follow visit for all three groups. The level change of troponin I from the baseline through the 3-month follow-up visit were $0.1(0.0-0.2), 0.2(0.1-$ $0.3)$, and $0.1(0.0-0.2)$ in the aforementioned three groups, respectively. $(P=0.453)$ The level change of NTproBNP from the baseline through the 3-month follow-up visit were 1175.8(885.6-1473.7), 1450.7(1009.51857.4), and 963.6(765.7-1255.7) in the aforementioned three groups, respectively. $(P=0.001)$ The level change of D-dimer from the baseline through the 3-month follow-up visit were 1932.4(1256.8-2674.2), 1460.4(1047.3-1884.7), and 611.4(478.5-833.7) in the aforementioned three groups, respectively. $(\mathrm{P}<$ 0.001) (Table 2)

\section{Third Outcomes}

The events of progressed fatal PE for which thrombectomy, vena cava filter insertion, or thrombolysis were performed or indicated during the 3-month treatment of acute PE were 6, 9, and 12 in the LMWH + rivaroxaban $(n=343), L M W H+$ dabigatran $(n=338)$, and $L M W H+$ warfarin $(n=329)$ groups, respectively. $(P$ $=0.404)$ The death from fatal PE during the 3-month treatment of acute PE were 3, 5, and 7 in the aforementioned three groups, respectively. $(P=0.310)$ The compelled anticoagulant reduction or cessation due to adverse events during the 3-month treatment of acute PE were 40, 47, and 52 in the aforementioned three groups, respectively. $(P=0.297)$

\section{Safety Outcomes}

The number of patients with major bleeding events were 3,6 , and 18 in the LMWH + rivaroxaban $(n=343)$, $\mathrm{LMWH}+$ dabigatran $(\mathrm{n}=338)$, and $\mathrm{LMWH}+$ warfarin $(\mathrm{n}=329)$ groups, respectively. The major bleeding rates were $0.9 \%, 1.8 \%$, and $5.5 \%$ in the aforementioned three groups, respectively. $(P<0.001)$

\section{Discussion}

In the current study, the results indicated that the resolution rate of acute PE on imaging after 3-month initial treatment in the $\mathrm{LMWH}$ + rivaroxaban group was similar to that in the $\mathrm{LMWH}+$ dabigatran group, which were both higher than that in the LMWH + warfarin group. No difference was found with respect to the prevalence of DVT at the 3-month follow-up visit among three group. The NT-proBNP and D-dimer level at the 3-month follow-up visit in the LMWH + rivaroxaban group were similar to those in the LMWH + dabigatran group, which were both lower than those in the LMWH + warfarin group, respectively. The level change of NT-proBNP and D-dimer from the baseline through the 3-month follow-up visit were similar to those in the LMWH + dabigatran group, which were both higher than those in the LMWH + warfarin group, 
respectively. The troponin I level and prevalence of $\mathrm{PH}$-likely patients at the 3-month follow-up visit were similar among three groups, respectively. The level change of troponin I from the baseline through the 3month follow-up visit were similar among three groups. During the 3-month treatment of acute PE, the events of progressed fatal $\mathrm{PE}$, the death from fatal $\mathrm{PE}$, and the compelled anticoagulant reduction or cessation due to adverse events were similar among three groups, respectively. The major bleeding rates were similar between the LMWH + rivaroxaban and LMWH + dabigatran groups, both being lower than that of the LMWH + warfarin group.

To our best knowledge, this is the first study that assessed the efficacy and safety of sequential subcutaneous LMWH followed by oral rivaroxaban therapy at a dose of $20 \mathrm{mg}$ once daily in the treatment of patients with acute pulmonary embolism. The comparable studies to the current one are lacking, despite there were some relevant studies. In an observational study, 99 patients with active cancer and an established VTE receiving sequential treatment of dalteparin(9 days [5-20 days]) and rivaroxaban(2.8 months [1-6 months]) were retrospectively reviewed. One (1.0\%) patient developed pulmonary embolism, and seven $(7.1 \%)$ patients suffered recurrent VTE, without major bleeding being observed, during the 6 months follow-up period. Sequential rivaroxaban after dalteparin regimen could effectively reduce the risk of VTE recurrence with well tolerance. ${ }^{9}$ In another retrospective study, no symptomatic recurrence or major bleeding events was encountered after 6-month follow-up among 49 patients with confirmed VTE receiving an initial therapy with 1 to 18 days of parenteral enoxaparin $(1 \mathrm{mg} / \mathrm{kg}$ twice daily) followed by oral rivaroxaban $20 \mathrm{mg}$ every day. It was effective and safe to treat patients with established VTE by using a regimen of enoxaparin followed by a dose of $20 \mathrm{mg}$ of rivaroxaban. ${ }^{10} \mathrm{In}$ an open-label, single-arm, multicentre study, no occurrence of VTE or bleeding events was encountered among 56 patients who had undergone elective unilateral primary total hip replacement(THR) or total knee replacement(TKR) and subcutaneous enoxaparin(40 mg once daily or $30 \mathrm{mg}$ twice daily) followed by oral rivaroxaban(10 mg once daily, 35 days for THR and 14 days for TKR) for post-operative thromboprophylaxis. Sequential $\mathrm{LMWH}$ and rivaroxaban regimen provided effective and well-tolerated strategy for thromboprophylaxis in patients undergoing THR/TKR surgery. ${ }^{11}$

The efficacy and safety of rivaroxaban monotherapy have been extensively validated in previous studies. In the EINSTEIN-PE trial, the symptomatic recurrent VTE events was $50(2.1 \%)$ in the rivaroxaban $(15 \mathrm{mg}$ twice daily for 3 weeks, followed by $20 \mathrm{mg}$ once daily) group ( $\mathrm{N}=2419)$ and $44(1.8 \%)$ in the standardtherapy(enoxaparin followed by an adjusted-dose vitamin $\mathrm{K}$ antagonist[VKA]) group $(\mathrm{N}=2413)$, during a 12-month follow-up. The principal safety outcome occurred in $249(10.3 \%)$ patients of the rivaroxaban group and $274(11.4 \%)$ ones of the standardtherapy group $(P=0.23)$. Rivaroxaban monotherapy was noninferior to standard therapy which was defined as sequential LMWH and VKA for the initial and longterm treatment of acute PE. ${ }^{7}$ In a propensity-matched cohort study, the incidence of recurrent VTE after 6month follow-up was 9.9 incidents per 100 person-years with rivaroxaban $(N=1734)$ and 13.1 incidents per 100 person-years with warfarin $(\mathrm{N}=2945)$ (hazard ratio [HR] 0.74 [95\% $\mathrm{Cl} 0.56-0.96])$. The incidence of major bleeding events was 2.4 per 100 person-years at 6 months with rivaroxaban versus 2.0 with warfarin (HR 1.19, 95\% $\mathrm{Cl}$ 0.66-2.13). Rivaroxaban was associated with reduced risk of recurrent VTE compared with standard regimen for patients with unprovoked VTE, without safety concerns. ${ }^{12}$ In addition, several 
studies demonstrated that rivaroxaban was similar to dabigatran for the treatment of acute VTE, in terms of VTE recurrence, VTE-related death, and all-cause mortality, except rivaroxaban seemed to result in a higher bleeding risk compared with dabigatran. ${ }^{13-16}$ The efficacy and safety of sequential LMWH followed by oral rivaroxaban at a dose of $20 \mathrm{mg}$ once daily in the current study are basically consistent with those of rivaroxaban monotherapy in previous studies.

The current study suffers from some limitations. First of all, it was a retrospective study. A prospective study is warranted in the future. Secondly, since rivaroxaban monotherapy ( $15 \mathrm{mg}$ twice daily for 21 days followed by $20 \mathrm{mg}$ once daily) is not a popular regimen in the participating hospitals even the whole country, there is no way to learn the results of head-to-head comparison between rivaroxaban monotherapy and sequential LMWH and rivaroxaban regimen. Thirdly, since patients receiving dabigatran at a dose of $110 \mathrm{mg}$ twice daily were not incorporated in the current study, the results may not applicable to this patient population.

In conclusion, the current study suggests that, compared with sequential LMWH plus warfarin and LMWH plus dabigatran, the regimen of sequential subcutaneous LMWH for a week followed by oral rivaroxaban at a dose of $20 \mathrm{mg}$ once daily for three months is effective and safe in the initial treatment of patients with acute pulmonary embolism. This finding may provide clinicians more options with respect to the initial treatment of patients with acute pulmonary embolism.

\section{Declarations}

\section{Ethics Approval and Consent to Participate}

The study protocol was approved by the institutional review boards of Shanghai Xinhua Hospital, Shanghai Pulmonary Hospital, and Shanghai Punan Hospital.

\section{Consent for publication}

Not applicable

\section{Availability of data and materials}

The datasets used and/or analysed during the current study are available from the corresponding author on reasonable request.

\section{Competing interests}

The authors declare no competing interests.

\section{Funding}

No funding was received for this work.

\section{Authors' Contributions}


WX was in full charge of the design of the study, the analysis and interpretation of the data, and the writing of the manuscript. YFZ, HD, YMW, XJG, WJL and SL contributed more or less to the study design, data analysis and interpretation, and the writing of the manuscript. All authors have read and approved the final manuscript.

\section{Acknowledgements}

Not applicable

\section{References}

1. Streiff MB, Holmstrom B, Angelini D, et al. NCCN Guidelines Insights: Cancer-Associated Venous Thromboembolic Disease, Version 2.2018. J Natl Compr Canc Netw. 2018;16(11):1289-303.

2. Konstantinides SV, Meyer G, Becattini C, et al. 2019 ESC Guidelines for the diagnosis and management of acute pulmonary embolism developed in collaboration with the European Respiratory Society (ERS). Eur Heart J. 2020;41(4):543-603.

3. Konstantinides SV, Meyer G, Becattini C, et al. 2019 ESC Guidelines for the diagnosis and management of acute pulmonary embolism developed in collaboration with the European Respiratory Society (ERS): The Task Force for the diagnosis and management of acute pulmonary embolism of the European Society of Cardiology (ESC). Eur Respir J. 2019;54(3):1901647.

4. Farge D, Frere C, Connors JM, et al. 2019 international clinical practice guidelines for the treatment and prophylaxis of venous thromboembolism in patients with cancer. Lancet Oncol. 2019;20(10):e566-81.

5. Key NS, Khorana AA, Kuderer NM, et al. Venous Thromboembolism Prophylaxis and Treatment in Patients With Cancer: ASCO Clinical Practice Guideline Update. J Clin Oncol. 2020;38(5):496-520.

6. Kearon C, AkI EA, Ornelas J, et al. Antithrombotic Therapy for VTE Disease: CHEST Guideline and Expert Panel Report. Chest. 2016;149(2):315-52.

7. Investigators EINSTEIN-PE, Büller HR, Prins $M H$, et al. Oral rivaroxaban for the treatment of symptomatic pulmonary embolism. N Engl J Med. 2012;366(14):1287-97.

8. Schulman S, Kearon C, Subcommittee on Control of Anticoagulation of the Scientific and Standardization Committee of the International Society on Thrombosis and Haemostasis. Definition of major bleeding in clinical investigations of antihemostatic medicinal products in non-surgical patients. J Thromb Haemost. 2005;3(4):692-4.

9. Chen L, Chen Q, Zhu M, Zhuang Z. Dalteparin and Rivaroxaban Sequential Use in Cancer Patients with Venous Thromboembolism. J Coll Physicians Surg Pak. 2021;31(3):294-7.

10. Wolosker N, Varella AY, Fukuda JM, et al. Enoxaparin Treatment Followed by Rivaroxaban for the Treatment of Acute Lower Limb Venous Thromboembolism: Initial Experience in a Single Center. Clin Appl Thromb Hemost. 2016;22(4):377-80.

11. Mills RM, Berkowitz RD, Damaraju CV, Jennings LK, Wildgoose P. Initiation of rivaroxaban following low molecular weight heparin for thromboprophylaxis after total joint replacement: the Safe, Simple 
Transitions (SST) study. Thromb Res. 2012;130(5):709-15.

12. Larsen TB, Skjøth F, Kjældgaard JN, Lip GYH, Nielsen PB, Søgaard M. Effectiveness and safety of rivaroxaban and warfarin in patients with unprovoked venous thromboembolism: a propensitymatched nationwide cohort study. Lancet Haematol. 2017;4(5):e237-44.

13. Rollins BM, Silva MA, Donovan JL, Kanaan AO. Evaluation of oral anticoagulants for the extended treatment of venous thromboembolism using a mixed-treatment comparison, meta-analytic approach. Clin Ther. 2014;36(10):1454-64.e3.

14. Mantha S, Ansell J. Indirect comparison of dabigatran, rivaroxaban, apixaban and edoxaban for the treatment of acute venous thromboembolism. J Thromb Thrombolysis. 2015;39(2):155-65.

15. Cohen AT, Hamilton M, Mitchell SA, et al. Comparison of the Novel Oral Anticoagulants Apixaban, Dabigatran, Edoxaban, and Rivaroxaban in the Initial and Long-Term Treatment and Prevention of Venous Thromboembolism: Systematic Review and Network Meta-Analysis. PLoS One. 2015;10(12):e0144856.

16. Jugrin AV, Hösel V, Ustyugova A, De Francesco M, Lamotte M, Sunderland T. Indirect comparison and cost-utility of dabigatran etexilate and rivaroxaban in the treatment and extended anticoagulation of venous thromboembolism in a UK setting. J Med Econ. 2016;19(1):1-10.

\section{Figures}




\begin{tabular}{|c|c|c|}
\hline & $\begin{array}{l}1223 \text { patients with } \\
\text { acute PE were } \\
\text { included }\end{array}$ & \\
\hline & $>$ & $\begin{array}{l}55 \text { ones with a history of } \\
\text { CTED were excluded } \\
158 \text { ones received } \\
\text { anticoagulation prior to the } \\
\text { baseline and/or other } \\
\text { anticoagulants during } \\
\text { follow-up were excluded }\end{array}$ \\
\hline$\downarrow$ & $\downarrow$ & $\downarrow$ \\
\hline $\begin{array}{l}343 \text { ones in the } \\
\text { LMWH+rivaroxaba } \\
n \text { group }\end{array}$ & $\begin{array}{l}338 \text { ones in the } \\
\text { LMWH+dabigatran } \\
\text { group }\end{array}$ & $\begin{array}{l}329 \text { ones in the } \\
\text { LMWH+warfarin } \\
\text { group }\end{array}$ \\
\hline$\downarrow$ & $\downarrow$ & $\downarrow$ \\
\hline $\begin{array}{l}297 \text { ones finished } \\
\text { 3-month treatment }\end{array}$ & $\begin{array}{l}282 \text { ones finished } \\
\text { 3-month treatment }\end{array}$ & $\begin{array}{l}265 \text { ones finished } \\
\text { 3-month treatment }\end{array}$ \\
\hline
\end{tabular}

Figure 1

Inclusion, Exclusion and Follow-up of Patients Note:PE:Pulmonary Embolism, CTED:Chronic Thromboembolic Disease, LMWH:Low Molecular Weight Heparin 

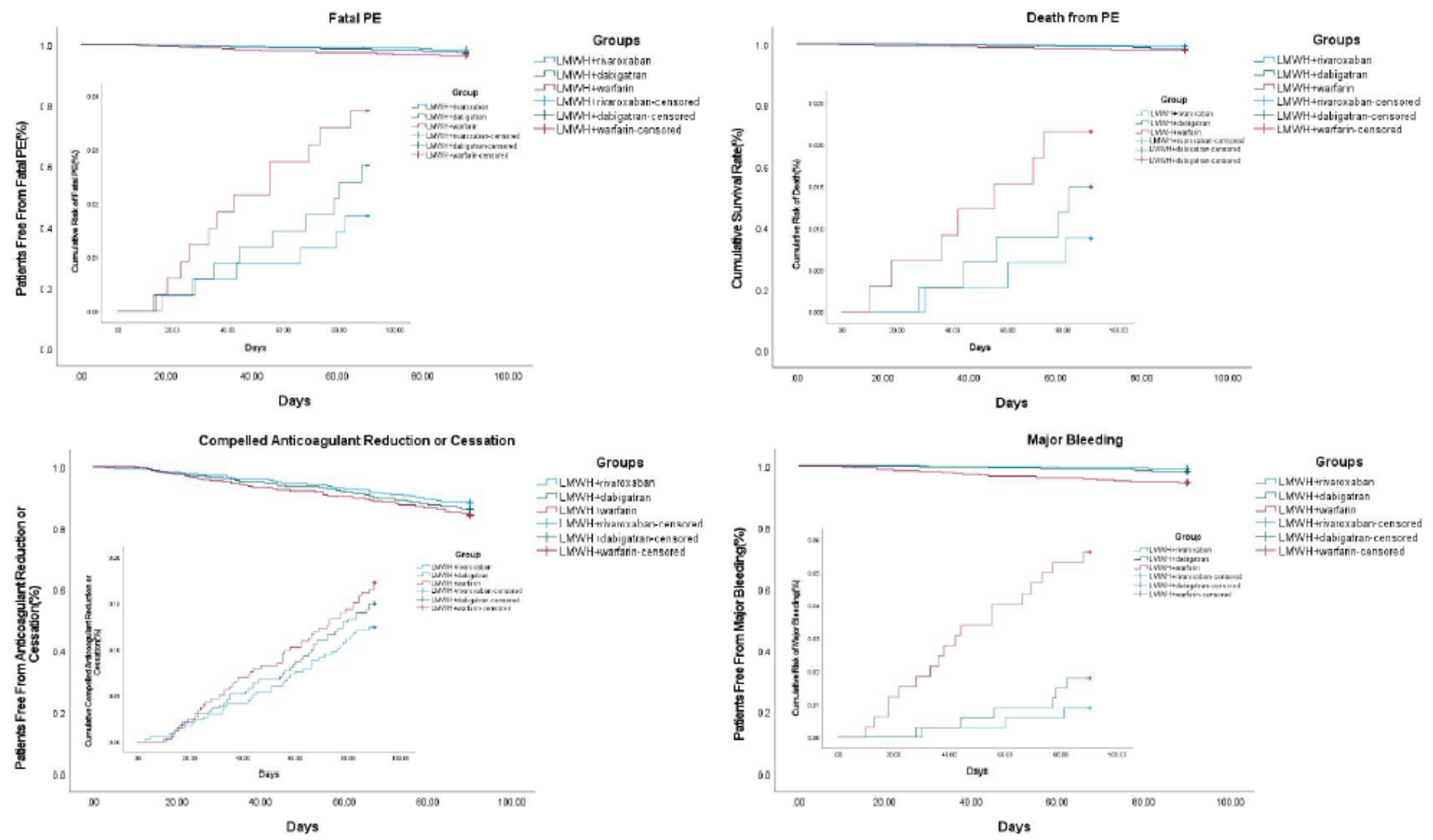

Figure 2

Third and Safety Outcomes During 3-month Follow-up Note:PE:Pulmonary Embolism, LMWH:Low Molecular Weight Heparin 